\title{
Ultrastructural and histochemical study of the digestive gland in cephalaspideans (Mollusca, Euopisthobranchia)
}

\author{
Lobo-da-Cunha, A. ${ }^{* * * *}$, Oliveira, E. , Alves, A. ${ }^{*}$ and Calado, G. ${ }^{* * *}$ \\ * Institute of Biomedical Sciences Abel Salazar (ICBAS), University of Porto, Portugal \\ ** Interdisciplinary Centre of Marine and Environmental Research (CIIMAR), Porto, Portugal \\ *** Lusophone University of Humanities and Technologies, Lisbon, Portugal
}

Email: alcunha@icbas.up.pt

Cephalaspideans are marine gastropods with or without external shell, now included in the clade Euopisthobranchia, comprising herbivorous and carnivorous species [1,2]. The digestive gland is the major organ of the digestive system of gastropods, formed by blind ending tubules (digestive diverticula). This organ is involved in extracellular and intracellular digestion, absorption of nutrients, storage and detoxification. The digestive diverticula are formed by digestive and basophilic cells, and in some species a few mucous cells are also present. For a comparative analysis, the digestive gland of cephalaspideans was studied in two herbivores (Bulla striata and Haminoea navicula) and in three carnivores (Philine quadripartita, Aglaja tricolorata and Philinopsis depicta). Samples were processed for transmission electron microscopy and semithin sections were used for light microscopy observations and histochemistry. Digestive cells are tall, club-shaped with a basal nucleus, being involved in intracellular digestion. Large lipid droplets are common in these cells and could be stained in semithin sections with Sudan black (Fig. 1). Since these lipids are highly osmiophilic, sections had to be treated with a $0.06 \% \mathrm{H}_{2} \mathrm{O}_{2}$ solution to remove the osmium tetroxide before staining with Sudan black. Food particles resulting from extracellular digestion are collected in cell membrane pits, included in vesicles and transported to endosomes. The digestion of food particles is completed in the lysosomes that are abundant and large in these cells (Fig. 2). Some images suggest the fusion of smaller lysosomes to create very large vacuoles filling almost the entire cell. Basophilic cells usually have a pyramidal shape; contain a large nucleus, many electron-dense secretory vesicles and several small vacuoles (Fig. 3). However, in B. striata, basophilic cells contain a single large secretory vesicle at the cell apex. In semithin sections, the tetrazonium coupling reaction revealed the presence of proteins in the secretory vesicles (Fig. 4) that also contain polysaccharides, being PAS positive (Fig. 5). These cells are considered responsible for secreting enzymes for extracellular digestion, being rich in rough endoplasmic reticulum (Fig. 6). Peroxisomes are common in the digestive gland, being more abundant and larger in basophilic cells (Fig. 7). In basophilic cells of $P$. depicta peroxisomes can reach approximately $5 \mu \mathrm{m}$ in diameter and contain a prominent core that can be seen with the light microscope in semithin sections. Peroxisomes are smaller in basophilic cells of $A$. tricolorata, although both species belong to the same family (Aglajidae). Considering the shape of core sections, in all these species peroxisomes seem to contain octahedral cores. Basophilic cells of $H$. navicula contain peroxisomes with two cores. Despite some differences, digestive and basophilic cells show similar features in all cephalaspidean species observed so far, being identical to the respective digestive gland cells of other gastropods. Thus, the fundamental morphofunctional features of this organ have been conserved during the evolution of most gastropod clades.

[1] Malaquias, M.A.E., et al. Zool. Scripta 38, 23-41, 2009.

[2] Malaquias, M.A.E., et al. J. Zool. 227, 88-97, 2009. 

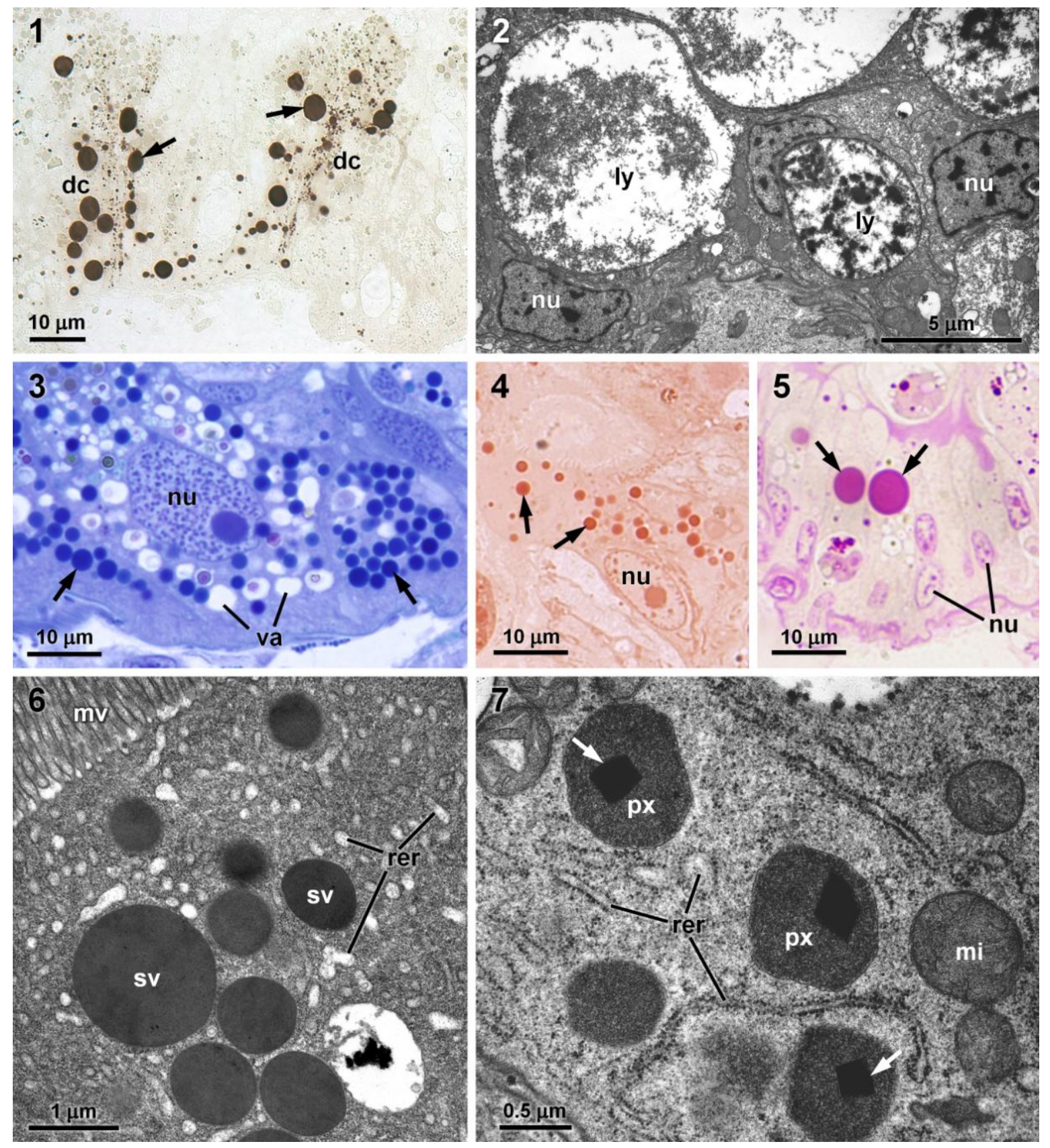

Fig. 1 Lipid droplets (arrows) in digestive cells (dc) of P. quadripartita in a semithin section stained with Sudan black. Fig. 2 Digestive cells of $A$. tricolorata showing large lysosomes (ly) and nuclei (nu). Fig. 3 Basophilic cells of $H$. navicula contain many secretory vesicles (arrows) and small vacuoles (va). Fig. 4 Basophilic cell of $P$. depicta showing several secretory vesicles stained by the tetrazonium reaction for proteins (arrows). Fig. 5 Large secretory vesicles in B. striata basophilic cells stained by PAS reaction (arrows). Fig. 6 Apical region of a basophilic cell of A. tricolorata showing microvilli (mv) and secretory vesicles (sv) surrounded by rough endoplasmic reticulum (rer). Fig. 7 Basal region of a basophilic cell of $B$. striata showing peroxisomes (px) with cores (arrows) and mitochondria (mi). 